\title{
ASSESSMENT OF IEC 61400-1 NORMAL TURBULENCE MODEL FOR WIND CONDITIONS IN TAIWAN WEST COAST AREAS*
}

\author{
TZONG-SHYNG LEU, JUI- MING YO, YI-TING TSAI, JIU-JIH MIAU, TA-CHUNG WANG \\ Department of Aeronautics and Astronautics, National Cheng Kung University \\ No. 1 University Road, Tainan 701, Taiwan \\ tsleu@mail.ncku.edu.tw \\ CHIEN-CHOU TSENG \\ Department of Mechanical and Electro-Mechanical Engineering, National Sun Yat-Sen University \\ 70 Lienhai Rd., Kaohsiung 80424, Taiwan \\ tsengch@mail.nsysu.edu.tw
}

Published 17 November 2014

\begin{abstract}
This paper studies the applicability of Normal Turbulence Model (NTM) in IEC61400-1 for wind conditions in Taiwan west coast area where future offshore wind farms are planning in the nearby areas. The parameters for the standard deviation of wind fluctuating $\left(\bar{\sigma} / I_{\text {ref }}\right)$ are presented and compared with IEC Normal Turbulence Model. It is found that the trend of turbulence standard deviation $\left(\bar{\sigma} / I_{\text {ref }}\right)$ based on the observation data agreed qualitatively well with IEC Normal Turbulence Model. However, IEC Normal Turbulence Model results in rather small $\sigma_{d} I_{\text {ref }}$ compared to surveillance wind data in Taiwan. In this paper, model parameters for $\bar{\sigma} / I_{\text {ref }}$ and $\sigma_{d} / I_{\text {ref }}$ based on the two-year observation wind data are proposed. The proposed model parameters $a, b, \alpha$ and $\beta$ are $0.9125,2.4345,0.097$ and 2.1875 .
\end{abstract}

Keywords: Wind Turbulence, Normal Turbulence Model, IEC61400-1.

\section{Introduction}

Atmospheric wind speed in natural environment changes all the time, and these changes in wind speed is known as wind turbulence. Wind turbines are subjected to wind turbulence that may affect their output power, loading, durability and operation life time. Therefore, the establishment of wind standard turbulence model is very important. In the international standard IEC61400-1 3rd edition [1] (hereinafter referred to as the IEC standard) mentioned a standard wind turbulence model for normal condition (Normal Turbulence Model NTM), referred to the wind turbulence model with the suggested parameter values. According to international standard IEC 61400-1, the wind conditions for a wind turbine design are typically divided into normal and extreme categories. The

\footnotetext{
* This is an Open Access article published by World Scientific Publishing Company. It is distributed under the terms of the Creative Commons Attribution 3.0 (CC-BY) License. Further distribution of this work is permitted, provided the original work is properly cited.
} 
normal wind conditions generally concern recurrent wind loading conditions, while the extreme wind conditions represent rare wind design conditions. The design load shall consist of potentially critical combinations of both normal and extreme wind conditions during wind turbine operation. Wind conditions are the primary loading conditions affecting structural integrity. Both normal and extreme conditions are considered for design of wind turbine. For normal wind conditions, wind fluctuation characteristics can have a large impact on the fatigue wind loading on wind turbine. Therefore the models of wind fluctuating velocity are very important on wind turbine design and operation.

Due to IEC standard is developed by most of European and American countries, it is always a question that if IEC standard is also applicable in East Asia countries. In Japan, T. Ishihara [2] explored the IEC61400-1 standard turbulence model parameter analysis by using the wind data observed on a Japan offshore gas drilling platform. The results indicate that the standard deviation $(\bar{\sigma})$ of wind fluctuation are similar with the IEC standard turbulence model, but the standard deviation of $\bar{\sigma}$ is far greater than the IEC standards suggested model parameter values. Recently, a demonstration incentive program for offshore wind energy is announced to encourage developers to set up three pioneering offshore wind farms in shallow water area (depth below $20 \mathrm{~m}$ ) near Taiwan west coast by 2015 . The capacity of each wind farm is 100-200 MW, and the government will provide TWD 250 million for the expense of wind farm development, as well as 50 $\%$ equipment subsidy for the first 2 turbines of each wind farm. With experiences gained from the development of the pioneering wind farms, the next step is to exploit deep water area (depth above $20 \mathrm{~m}$ ) in mass production scale. It is scheduled that 450 onshore wind turbines of 1,200 MW can be established by 2020, and 600 offshore wind turbines of $3,000 \mathrm{MW}$ by 2030 . The total accumulated capacity adds up to 4,200 MW, which makes up $33 \%$ of the renewable energy promotion target.

Since Taiwan is located in a very special geographical and natural environment region, Offshore wind farms in Taiwan need to face the test of typhoons, earthquakes, walrus, weather and other harsh conditions. The international IEC standard turbulence model may not necessarily meet the special meteorological wind conditions of Taiwan. Therefore, this paper studies the IEC standard turbulence model and its applicability to Taiwanese wind condition, hoping to find out the suitable turbulence model parameters as a reference for the future offshore wind farms in Taiwan.

\section{Method of Analysis}

\subsection{Introduction of International Standard IEC 61400-1 and IEC 61400-12}

According to IEC 61400-12 international standard [3], wind data shall be collected continuously at a sampling rate of $0.5 \mathrm{~Hz}$ or faster. The data acquisition system shall store either sampled data or pre-processed data sets as described below, or both. The preprocessed data sets shall comprise the following information on the sampled data including mean value, standard deviation, maximum value and minimum value. The total duration of each pre-processed data set shall be between $30 \mathrm{~s}$ and $10 \mathrm{~min}$ and shall be 10 
min divided by an integer number. The preprocessed data will be stored and processed to final selected data. The selected data sets will be based on 10 min periods derived from contiguous measured data. The mean, standard deviation and turbulence intensity values for each 10 min period shall, when derived from preprocessed data sets, be calculated according to the following equations:

$$
\begin{gathered}
\bar{U}=\frac{1}{N_{k}} \sum_{1}^{N_{k}} U_{k} \\
\bar{\sigma}=\sqrt{\frac{1}{N_{k} N_{s}-1} \sum_{1}^{N_{k}}\left(N_{s}\left(\bar{U}-U_{k}\right)^{2}+\sigma_{k}^{2}\left(N_{s}-1\right)\right)} \\
I=\bar{\sigma} / \bar{U}
\end{gathered}
$$

where $N_{k}$ is the number of pre-processed data sets within a $10 \mathrm{~min}$ period. $U_{k}$ is the averaged wind speed over pre-processing time period. $\bar{U}$ is the averaged wind speed over $10 \mathrm{~min} . N_{s}$ is the number of data samples of pre-processed data sets. $\sigma_{k}$ is the standard deviation of pre-processed wind speed. $\bar{\sigma}$ is the standard deviation of preprocessed wind speed averaged over $10 \mathrm{~min} . I$ is the turbulence intensity of wind speed over $10 \mathrm{~min}$.

About wind turbulence, Normal Turbulence Model (NTM) is presented in IEC 61400-1 standard for normal wind condition. According to NTM, the representative value of the turbulence standard deviation, $\sigma_{l}$, shall be given by the $90 \%$ quantile for the given hub height wind speed. The estimated turbulence standard deviation $(\bar{\sigma})$ and the standard deviation of estimated turbulence standard deviation $\left(\sigma_{\sigma}\right)$ can be expressed as:

$$
\begin{aligned}
& \bar{\sigma}=I_{r e f}(a \bar{U}+b) \\
& \sigma_{\sigma}=I_{r e f}(\alpha \bar{U}+\beta)
\end{aligned}
$$

where $I_{\text {ref }}$ is the expected value of hub-height turbulence intensity at a 10 min average wind speed of $15 \mathrm{~m} / \mathrm{s} . a, b, \alpha$ and $\beta$ are the model parameters. Values for $I_{r e f}, a, b, \alpha$ and $\beta$ are given in Table 1. As shown in Table $1, I_{\text {ref }}$ value in the IEC 61400-1 standard varies with turbulence intensity of the wind turbine construction site, but the values of NTM parameters $a, b, \alpha$ and $\beta$ are fixed $0.75,3.8,0$ and 1.4.

Table 1. Parameters for Normal Turbulence Model.

\begin{tabular}{|c|c|c|c|c|c|}
\hline & $I_{\text {ref }}$ & $a$ & $b$ & $\alpha$ & $\beta$ \\
\hline IEC Class A & 0.16 & & & & \multirow{2}{*}{0.75} \\
\cline { 1 - 2 } IEC Class B & 0.14 & 3.8 & 0 & 1.4 \\
\hline IEC Class C & 0.12 & & & & \\
\hline Period 1 & 0.098 & 0.912 & 2.423 & 0.100 & 2.316 \\
\hline Period 2 & 0.099 & 0.913 & 2.446 & 0.094 & 2.059 \\
\hline$($ Period 1+Period 2)/2 & 0.0985 & 0.9125 & 2.4345 & 0.097 & 2.1875 \\
\hline
\end{tabular}

The averaged wind speed $(\bar{U})$ data set will be sorted using the "method of bins" procedure. "Method of bins" will divide the wind speed range into $0.5 \mathrm{~m} / \mathrm{s}$ contiguous bins centered on integer multiples of $0,5 \mathrm{~m} / \mathrm{s}$. For each bin, the probability density function (PDF) of the averaged wind speed data $(\bar{U})$ is calculated. Assuming the normal 


\section{T. S. Leu et al.}

distribution of turbulence standard deviation, 90th percentile $\left(\sigma_{90}\right)$ of the turbulence standard deviation can be expressed as:

$$
\sigma_{90}=\bar{\sigma}+1.28 \sigma_{\sigma}
$$

Therefore, the 90th percentile of the turbulence intensity $\left(I_{90}\right)$ can be formulated as:

$$
I_{90}=\frac{\sigma_{90}}{\bar{U}}=I_{r e f}\left\{a+1.28 \alpha+\frac{(b+1.28 \beta)}{\bar{U}}\right\}
$$

Table 2. Specification of wind sensor and data logger system.

\begin{tabular}{|l|l|l|}
\hline \multirow{4}{*}{$\begin{array}{c}\text { Wind } \\
\text { anemometer }\end{array}$} & Manufacturer & R. M. Young Company, USA \\
\cline { 2 - 3 } & Model number & 05103 \\
\cline { 2 - 3 } & Type & propeller-vane \\
\cline { 2 - 3 } & Wind direction range (accuracy) & 360 degrees $( \pm 3$ degrees) \\
\cline { 2 - 3 } & Wind speed range (accuracy) & $0-100 \mathrm{~m} / \mathrm{s}( \pm 0.3 \mathrm{~m} / \mathrm{s})$ \\
\hline \multirow{5}{*}{ Data logger } & Manufacturer & Campbell Scientific, USA \\
\cline { 2 - 3 } & Model number & CR-1000 \\
\cline { 2 - 3 } & Sampling rate & $1 \mathrm{~Hz}$ \\
\cline { 2 - 3 } & Preprocessed observation data & $1-$ minutes average wind speed and direction \\
\cline { 2 - 3 } & & $1-$-minutes wind speed standard deviation \\
\cline { 2 - 3 } & \multirow{2}{*}{ Observation period } & $\begin{array}{l}\text { Feb. 2010 Jan. 2011 (Period 1) } \\
\text { Feb. 2011 Jan. 2012 (Period 2) }\end{array}$ \\
\hline
\end{tabular}

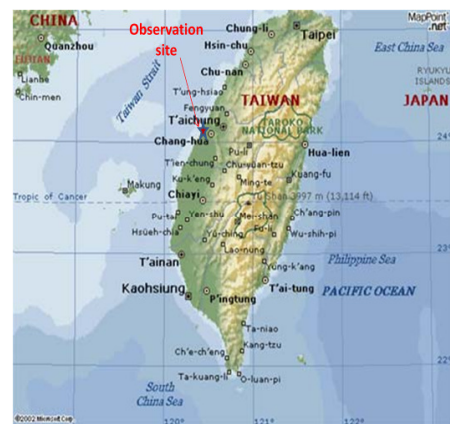

(a)

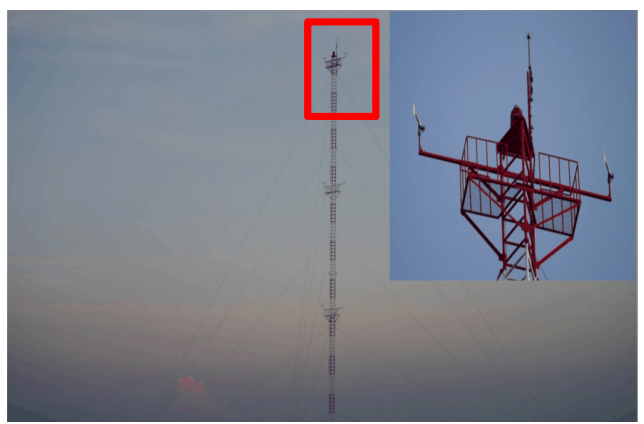

(b)

Fig. 1. (a) On-shore observation site (b) Wind mast with wind anemometers.

\subsection{Brief of wind data collection and analysis}

The wind data used in this study are collected from the wind mast of the Taiwan Power Company located in Chang-hua coast (Figure 1). Wind sensors are installed at 70 meter height of the mast, roughly the same as the hub height of a typical wind turbine. Wind anemometer (RM Young Company Model 05103) is a four blade propeller-vane type anemometer. Model CR-1000 data logger system from Campbell Scientific Company is used for the wind data acquisition. Related wind anemometer and data logger specifications are shown in Table 2. The sampling rate of data logger is $1 \mathrm{~Hz}$. Observation period in this study is from February 2010 to January 2012. Total of two years wind data are collected. In this paper, the observation period from February 2010 to 
January 2011 is called "Period 1 observation" and from February 2011 to January 2012 is called "Period 2 observation". In order to comply with IEC international standard, wind data are processed as the 10-min mean wind speed $(\bar{U})$ and 10-min averaged standard deviation $(\bar{\sigma})$ by using Eq. (1) and Eq. (2). In addition, in order to explore the annual change of wind speed and direction, wind data of "Period 2" observation is used to validate the model parameters proposed from the "Period 1 " observation data.

\section{Results and Discussion}

\subsection{Wind direction, wind speed and turbulence distribution of the observation data}

Figure 2 shows the probability density function (PDF) of the average wind speed and rose map of wind direction from the statistical analysis of "Period 1" observation data. As shown in Figure 2(a), the annual average wind speed of the "Period 1" observation data is about $U_{\text {avg }}=8.46 \mathrm{~m} / \mathrm{s}$. The duration of wind speed that exceeds $10 \mathrm{~m} / \mathrm{s}$ within the fullyear accounts for about 33\%. We can see the wind resource near Chang-hua coastal area of Taiwan is very good. To a better understanding of atmospheric wind speed distribution of Chang-hua coastal area, the Weibull distribution recommended by the IEC international standards is applied to the wind speed PDF distribution of the observation data, as shown in Fig. 2(a). The dimensionless Weibull equation is depicted as follows:

$$
\rho\left(\frac{\bar{U}}{U_{\text {avg }}}\right)=k \Gamma\left(1+\frac{1}{k}\right)\left\{\frac{\bar{U}}{U_{\text {avg }}} \Gamma\left(1+\frac{1}{k}\right)\right\}^{k-1} e^{-\left\{\frac{\bar{U}}{U_{\text {avg }}} \Gamma\left(1+\frac{1}{k}\right)\right\}^{k}}
$$

where $\bar{U}$ is10-minute mean wind speed. $U_{a v g}$ is the annual average wind speed. $\rho\left(\bar{U} / U_{\text {avg }}\right)$ is the dimensionless probability density function (PDF). $k$ is the shape factor of Weibull distribution. $\Gamma(1+1 / k)$ is gamma function. The values of the shape factor $k$ must be obtained first in order to achieve the best curve fitting of the wind speed PDF data. The shape factor can be obtained from Eq. (9) as shown below:

$$
k=\left(0.9874 /\left(\frac{\sigma}{U_{\text {avg }}}\right)\right)^{1.0983}
$$

where $\sigma$ is standard deviation of annual wind speed distribution.

After analysis, the ratio between annual standard deviation and the annual mean wind speed $\left(\sigma / U_{\text {avg }}\right.$ ) is about 0.697 . Weibull's shape factor $\mathrm{k}=1.466$ can be obtained by using Eq. (9). Finally, as shown the red curve in Figure 2(a), Weibull distribution curve (Eq. (8)) of the observation data can be fitted with the shape factor $k=1.466$. For a typical wind turbine (for example Vestas V80 / 2MW), the cut-in and cut-out wind speeds for power generation are $4 \mathrm{~m} / \mathrm{s}$ and $25 \mathrm{~m} / \mathrm{s}$. Wind energy can be exploited accounting for up to $73 \%$ during the "Period I". Although most of the wind distribution falls within the bell-shape envelope of the Weibull distribution, PDF of wind speed distribution in Taiwan does not fully comply with the Weibull curve. The wind PDF distribution in Taiwan presents a bimodal distribution, a continuous probability 


\section{T. S. Leu et al.}

distribution with two or more modes. About wind direction of Taiwan west coastal areas, the main wind direction is north-north-east (NNE) direction, accounting for about $45 \%$ of the full-year observation data. Especially the NNE wind occurrence frequency can be as high as $70 \%$ during winter time in Taiwan and most of the wind in summer time is from south, accounting for about $20 \%$. The wind speed and direction analysis for "Period 1" and "Period 2" observation data have similar results. This means that the annual wind energy that can be utilized is quite stable. The statistics analysis results are shown in Table 3.

Table 3. Analysis results of "Period 1" and "Period 2" observation data.

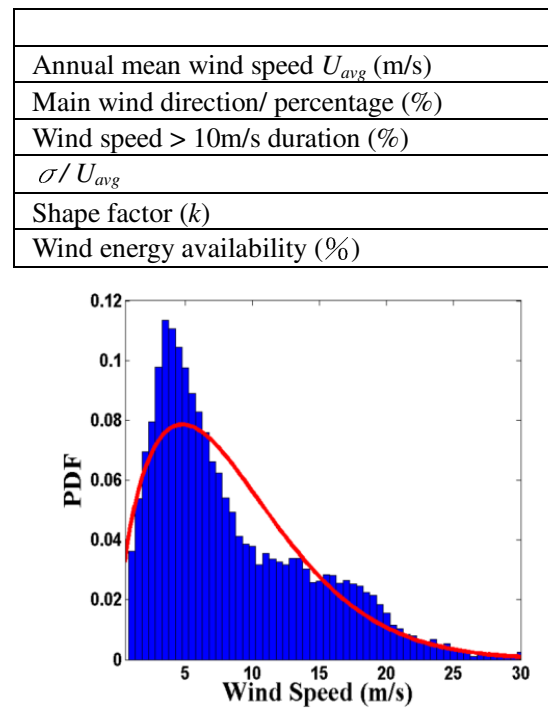

(a)

\begin{tabular}{|c|c|}
\hline Period 1 & Period 2 \\
\hline NNE / $44.5 \%$ & NNE / $49 \%$ \\
\hline 33 & 35 \\
\hline 0.697 & 0.678 \\
\hline 1.466 & 1.511 \\
\hline $73 \%$ & $74 \%$ \\
\hline
\end{tabular}

(b)

Fig. 2. Wind condition characteristics (a) PDF distribution of wind speed (b) Wind rose.

Figure 3 shows turbulence intensity distribution at different wind speeds. Figure 3(a) present the turbulence intensity distribution for "Period 1" observation data. Solid squares in Fig. 3(a) present the 90th percentile value of the wind turbulence intensity during "Period 1". IEC 61400-1 Category A, B and C are the wind turbulence intensity classifications in IEC 61400-1 international standard. IEC 61400-1 standard suggested $I_{\text {ref }}$ model parameter for Category A, B and C are $0.16,0.14$ and 0.12 respectively. As shown in Fig. 3(a), 90\% percentile turbulence intensity $\left(I_{90}\right)$ values of IEC 61400-1 Category B can contain the 90th percentile values of turbulence intensity for "Period 1" observation data. It means that $90 \%$ turbulence intensity values in Taiwan fall within the scope of the IEC Class B. As shown Fig. 3(b), the 90th percentile values of turbulence intensity for "Period 2" data have a similar observation as Period 1. The 90th percentile values of turbulence intensity for "Period 1" and "Period 2" are almost overlap, which means that turbulence intensity variation falls within the IEC international standard Class B for twoyear period of observation in Taiwan. 


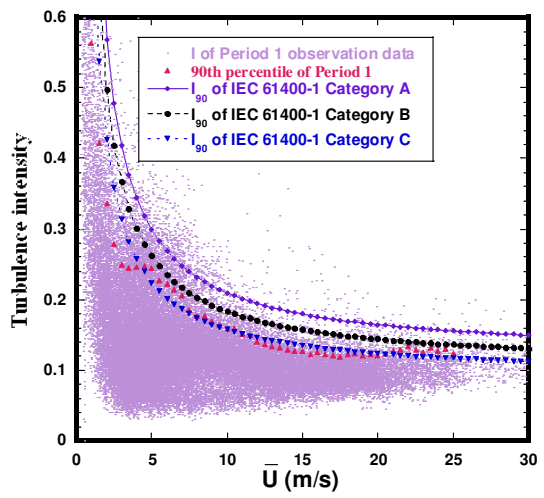

(a)

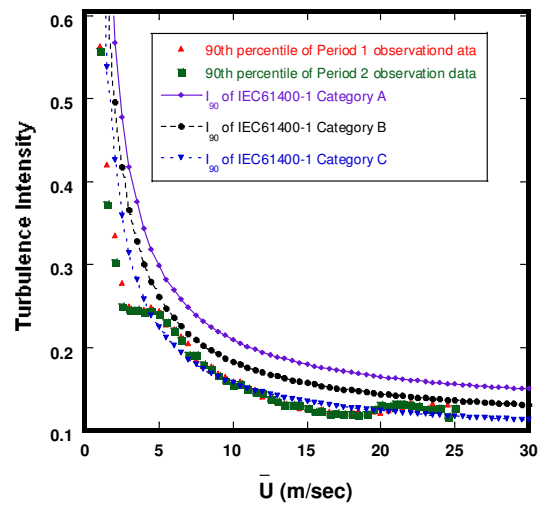

(b)

Fig. 3. (a) Variation of turbulence intensity with wind speed for "Period I" observation, (b) Comparison of the $90^{\text {th }}$ percentile values of turbulence intensity for "Period 1" and "Period 2" with IEC standards.

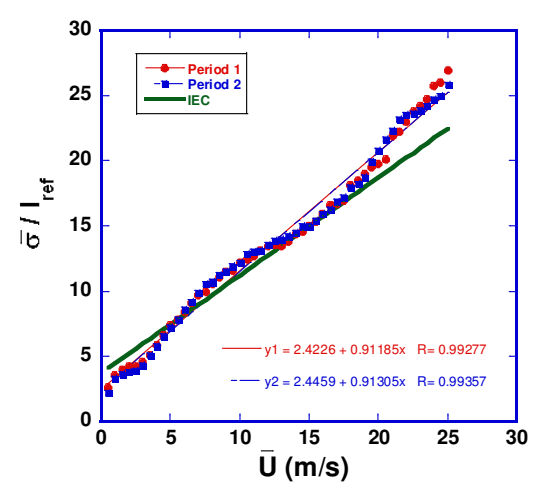

(a)

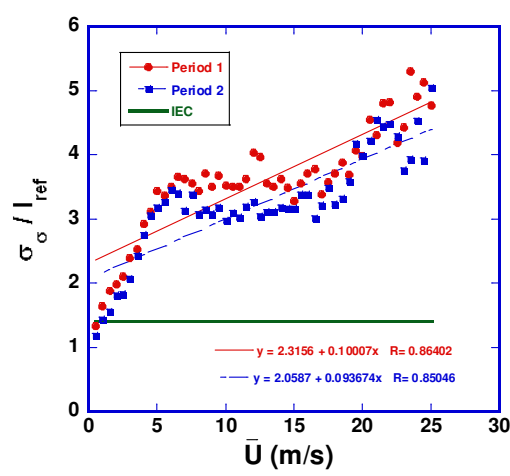

(b)

Fig. 4. Comparison of the observed distribution of (a) $\bar{\sigma} / \mathrm{I}_{\mathrm{ref}}, \&$ (b) $\sigma_{\sigma} / \mathrm{I}_{\mathrm{ref}}$ with IEC standards.

\subsection{IEC61400-1 Normal Turbulence Model parameters of the observation data}

Fig. 4(a) and Fig. 4(b) show the $\bar{\sigma} / I_{\text {ref }}$ and $\sigma_{\sigma} / I_{\text {ref }}$ for different wind speeds. The parameters $a, b, \alpha$ and $\beta$ are obtained from the slope and intercept of linear approximation in Fig. 4(a) and Fig. 4(b) by using the least square curve fitting method. Table 1 lists the parameters $a, b, \alpha$ and $\beta$ from the two-year observation data, as well as the model parameter values suggested by IEC 61400-1 standard. It can be noted from Fig. 4(a), $\bar{\sigma} / I_{\text {ref }}$ value will be less than the IEC NTM when the wind speed is less than $5 \mathrm{~m} / \mathrm{s}$. When the wind speed is higher than $5 \mathrm{~m} / \mathrm{s}, \bar{\sigma} / I_{\text {ref }}$ values will be greater than or equal to the IEC NTM. After linear curve fitting with Eq. (4), the values of the parameters $(a, b)$ are $(0.912,2.423)$ for the observation data of "Period 1 " and $(0.913,2.446)$ for the observation data of "Period 2". For both period observation data, they are very similar. However, $\sigma_{\sigma} / I_{\text {ref }}$ distribution in Fig. 4(b) shows a very different distribution from IEC 
Normal Turbulence Model. IEC Normal Turbulence Model results in rather small $\sigma_{\sigma} / I_{\text {ref }}$ values compared to surveillance wind data in Taiwan. As shown in Fig. 4(b), $\sigma_{\sigma} / I_{\text {ref }}$ values increase as the wind speeds increase for wind speeds $U<6 \mathrm{~m} / \mathrm{s}$ and $U>17 \mathrm{~m} / \mathrm{s}$. For wind speeds within $6 \mathrm{~m} / \mathrm{s}<\mathrm{U}<17 \mathrm{~m} / \mathrm{s}, \sigma_{\sigma} / I_{\text {ref }}$ value is a constant about 3.6 for observation "Period 1" and 3.2 for the observation "Period 2". After linear curve fitting with Eq. (5), the values of the parameters $(\alpha, \beta)$ are $(0.1,2.316)$ for the observation data of "Period 1" and $(0.094,2.059)$ for the observation data of "Period 2". After averaging the values of these two periods, the parameters $(a, b, \alpha, \beta)$ are $(0.9125,2.4345,0.097$, 2.1875) and listed in Table 1.

\section{Conclusions}

In this study, two-year wind data collected at the mast in the Chang-hua coastal areas are used to investigate the applicability of IEC normal turbulence model. After comparison between analysis results of measuring data and the IEC standard turbulence model, the following conclusion can be addressed:

1. The wind resource of the future offshore wind farms near Chang-hua coastal area is very good. The mean annual wind speed can reach $8.53 \mathrm{~m} / \mathrm{s}$. The main wind direction is NNE wind. The time of wind energy to be exploited is approximately $73.5 \%$ of time per year.

2. Based on two-year observation data, the wind turbulence level in Taiwan is IEC 61400-1 Category B. This result can be used as a reference for future offshore wind turbine selection.

3. The model parameters $a, b, \alpha$ and $\beta$ are $0.9125,2.4345,0.097$ and 2.1875 based on two-year observation data. They are quite different from the suggested normal turbulence model parameter values $a, b, \alpha$ and $\beta$ are $0.75,3.8,0.0$ and 1.4 by IEC.

\section{Acknowledgments}

This research is, in part, supported by the Ministry of Education, Taiwan, R. O. C. under The Aim for the Top University Project to the National Cheng Kung University (NCKU) and partial funding from National Science Council, R.O.C. under the contract of NSC 102-3113-P-006-011 and NSC 102-3113-P-006-005. Wind data provided by Taiwan Power Company are also appreciated.

\section{References}

[1] IEC 61400-1, Ed.3, Wind Turbine-Part 1: Design requirements, 2005.

[2] T. Ishihara, A. Yamaguchi, S. Oikawa and M. W. Sarwar, A Study of the Normal Turbulence Model in IEC61400-1, Wind Energy, Vol. 96, 2010, pp.142-147.

[3] IEC 61400-12, Ed.1, Wind turbine generator systems-Part 12: Wind turbine power performance testing, 1998. 